\title{
BRIDGING THE GAP BETWEEN GLOBAL AND LOCAL STRATEGIES OF ARCHITECTURAL CONSERVATION, EXAMPLES OF THE CURRENT SCENARIOS IN INDIA.
}

\author{
Manogna Kavuru \\ Department of Architecture, Built environment and Construction Engineering, Politecnico di Milano - Lecco, \\ manogna.kavuru@mail.polimi.it
}

KEYWORDS: Maintenance, Indian Context, Indian Temples. Monitoring, Latest Technologies, Image Based Diagnostics

\begin{abstract}
:
Culture develops from a civilization and progresses through the generations in tangible and intangible forms affecting various aspects of living. It gradually becomes a rulebook that guides the way of life for some people. This holds true in the Indian Society, which is punctuated by constant incorporation of migrating people with the diverse cultures that surround India. Such illustrious past should predict augmented conservation efforts. However, that is not the case. Following the Hindu philosophy of the life cycle, buildings are allowed to be deteriorating over the passage of time. It was only much later that the occidental influence of the British Empire encouraged conservation of built heritage. Yet today these efforts are absent at the most basic levels. On one side are the international organizations such as UNESCO providing guidelines for protection of these buildings and the on the other side are the government and non-government organizations which help maintain the structures. Co-relation between the two levels of conservation are non-existent in a way that initiatives by the government focus on improving infrastructure but neglect the Risk-assessment of the buildings. Such examples will be discussed further in the paper with suggestions to improve the situation with the help of new technologies and simplified methods that include making conservation education easier for even the most rural population. The research explores avenues of diagnosis integrated in the Italian philosophy of conservation to make maintenance more easy and effective.
\end{abstract}

\section{INTRODUCTION}

Culture develops from a civilization and progresses through the generations in tangible and intangible forms affecting various aspects of living. It gradually becomes a rulebook that guides the way of life for some people. This holds true in the Indian Society, which is punctuated by constant incorporation of migrating people with the diverse cultures that surround India. With a glorious and illustrious history, one would expect plentiful opportunities for conservation practices in India. However, this was not the case. While nations across the world have volumes written in history about their conservation efforts, Indians followed a different principle that was based on the cyclical notion of time with underlining references to Rebirth, which was called Jeernodhara (Srivathsan, 2011). This meant that significance was not given to a particular building or the material but to the site it was built on. For example, an old broken place of worship could be rebuilt to serve the same purpose. It was only during the British rule, i.e., in late 19th century; baby steps towards the occidental methods of conservation were introduced, starting with the protection of public buildings that were under the threat of misuse. The Architectural Survey of India (ASI) was established in 1861, to introduce legal provision to protect historical structures in India. In 1984, Indian National Trust for Art and Cultural Heritage (INTACH) was founded to inspire awareness for conservation of cultural heritage among the people (Government of India, 2013).

Today globalization and augmented networking is shrinking boundaries between countries making conservation of traditions and culture imperative. Hence, agencies like the UNESCO (United Nations Education Scientific and Cultural Organization) and ICOMOS (International council on monuments and sites) have been established with the aim to protect cultural and natural heritage and raise awareness regarding the same. Over the years their efforts have produced positive results on a larger scale.

International treaties offer protection to mostly endangered monuments; efforts made towards the maintenance of existing structures are mostly meager. Today there are many buildings especially temples which have been built in centuries past and yet are still used by people as places of worship. There are different trusts and departments of the government that are formed to save such monuments, but maintenance provided by them seems inadequate at best. On an international level; global strategies and treaties offer guidelines of protection based on a neutral baseline, which is expected to work in every place. Cultural and traditional implications that govern the day-to-day activities in the region are often overlooked (Architecture Imprints, 2004).

Initiatives introduced in India towards heritage conservation like HRIDAY (Heritage City Development and Augmentation Yojana) (Government of India, 2015) are mostly along the lines of improving the infrastructure; they accentuate on drainage lines and shelters for people visiting but not about the monument itself. For strengthening the structures, repair and maintenance there are not steady procedures and shared methodology for studying and diagnostics for the damage in advance of the maintenance. 
Risk assessment is predominantly deficient (seismic, humidity, interaction with environment, usage and number of visitors to the monument, rituals happening there that explain the cause of cleaning required). Within a general political overview regarding the strategies for improving the physical conservation of cultural heritage, in a top-down perspective, there have been new initiatives such as the Swachh Bharat Abhiyan (Government of India, 2014), a campaign introduced with the aim to clean the country, having the cleaning up of heritage monuments as one of its objectives. (YOUNGINTACH, 2016) However, the word 'cleaning' is used in an ambiguous way when the issue of maintenance is roused. For example, the commonly found historic buildings in India are temples. A visit to most of the functioning Indian temples reveals the floors to be greasy and walls covered in soot. Traditional rituals are followed every day in these places of worship; cleansing and purifying the place, being included in them. However, they are to be done in precise and in concise ways as mentioned in historical scriptures (TTD, 2015), that are generally very basic in nature and do not aid the needs of an ageing building since they were designed in historic times when there was no inclination to protect the monument for future generations, which is not the case anymore.

The Research makes use of exportable procedures of documentation, assessment and diagnostics that will improve the effectiveness of both repair and maintenance especially for the spread of cultural heritage that usually is not under the government protection and is more exposed to risk factors. These tools belong to the Italian philosophy, perspective of planned conservation (an example can be made from, Urbani, the pilot plan of Umbria (1976); (Della Torre, 2010)(Rosina, Diagnostics for the preservation plans of diffused historical heritage, 2010) and aim of their development is in 2000 until now has many similarities with the possible application in many areas in India, where there are grassroots processes for the conservation of the local cultural heritage (Architecture Imprints, 2004). Preliminary assessment and damage detection combined with image based diagnostics such as remote sensing, infrared thermography and photogrammetry etc., along with crack assessment through ultrasound testing could improve the risk assessment and these belong to the tools of knowledge of the plan of conservation. (Rosina, Diagnostics for the preservation plans of diffused historical heritage, 2010)

One of main objectives would be creating awareness of the possible harm that could be caused unintentionally, by emphasizing on the need for more effective maintenance and monitoring plans since it is a more feasible and inexpensive initiative towards conservation. Emphasis should be given to the rural context; where conservation education could be broken down to easier understandable terms would be helpful. The paper discusses various examples of such scenarios where small but effective changes in the existing maintenance routines that could bring about better results towards conserving the buildings.

\section{INDIAN SCENARIOS - CASE STUDIES}

Today, in India, Temples in large numbers can be found in every city and even in small villages. This could be because Early Indian architecture was a form of interpretation of the religious beliefs of the people. Indian temples are not only the abode of worshipping, but they are also the places where knowledge, art, architecture and culture flourished, as evidenced even today (Vardia, 2008). The rituals and traditions of temples exist not only in antiquity but also in recent times, which greatly influence the socio- cultural aspect of the current generation and give a connection to traditional Indian morals. Such significance attached to temples could play a pivotal role in rising awareness amongst the population about the importance of conservation and maintenance of cultural heritage, hence the focus on temples.

This study initiates from the need for a change in the approach of maintenance and monitoring of historic structures in India. In the past few years there have been many incidences where lack of proper maintenance, resources and knowledge of conservation procedures have caused immeasurable damage to many historic structures (Architecture Imprints, 2004), the case studies discussed here are two such examples of recent times, where superficial maintenance and lack of monitoring have caused catastrophic damages to the buildings. The two buildings being considered here are temples that belong to the south of India and the following section expounds on the background of temple architecture for better understanding of the typology of such buildings.

\subsection{Characteristics of Temple Architecture}

Hindu temples have retained the architectural style from ages past. Ancient treaties such as Vastushastra (ancient Indian treaty to help integrate the dwelling space with the surroundings) dictate the construction processes of Hindu temples, which adhere to concepts of Hindu cosmology. This system was adopted so that temples built in various locations still have congruity despite the distance between them, yet reflected the local style too. (Koduveliparambil, 1997)

Temple design can be broadly classified into 'Nagara' - North Indian style and 'Dravidian' - South Indian style; this study is primarily limited to the latter style of Temples. The Dravidian or the South Indian style temples mostly are square or rectangular shaped in plan and entail almost customarily of the following four parts, divergent only in few places based on the location and the age in which they were built:

- The principle component is the temple itself and is called the Vimana. It is almost always square in plan and surmounted by a roof that is pyramidal; it contains the sanctum where the idol of the god or his emblem is located.

- $\quad$ The porticos are called as Mandapas or Mantapams, they are provided to shade the entrance of the inner sanctum.

- The gateways also known as the Gopurams that are the fundamental features in the quadrangular enclosures that surround the temples. The size of the Gopurams change from temple to temple.

- $\quad$ Pillared halls otherwise known as Chaultris were used for various purposes; historically people who used to visit from far off places used it as resting places. 
Besides these, a temple always comprises of temple tanks or wells for water (used for the daily rituals in the temple and for the basic ablutions of the people who visit them temple);

Sometimes dwellings of the priests were attached to this area for the sake of convenience.

(Fergusson, 1910)(Vardia, 2008)

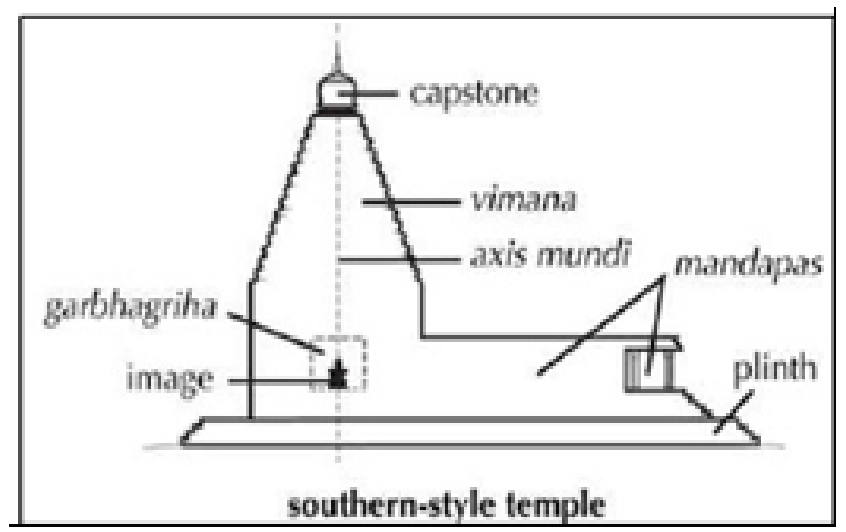

Figure 1 Elements of Dravidian Style Temple (Vardia, 2008)

\subsection{CASE-STUDY 1 - SRI KALAHASTHI TEMPLE, Andhra Pradesh, India}

\subsubsection{General information - History}

Srikalahasthi is a small town that houses the namesake temple; it is located in Chittoor district of the South Indian state of Andhra Pradesh and has the location co-ordinates $13.76^{\circ} \mathrm{N} 79.70^{\circ} \mathrm{E}$. It is situated along the banks of the river Swarnamukhi. This temple worships the lord Shiva, one of the principal deities of Hinduism.

The Temple was constructed during the Pallava Period of the 10$11^{\text {th }}$ century and most of the current remaining structures were made under the reign of the King Kulathuna Chola during the end of the $11^{\text {th }}$ century. Later additions included a hundred pillared mandapam or portico commissioned by Sri Krishnadevaraya of the Vijayanagara Dynasty during the $16^{\text {th }}$ century. The main temple is carved out of a single stone hill and the later added parts were made of brick masonry with stone supports at some significant places (Chandra, 2000).

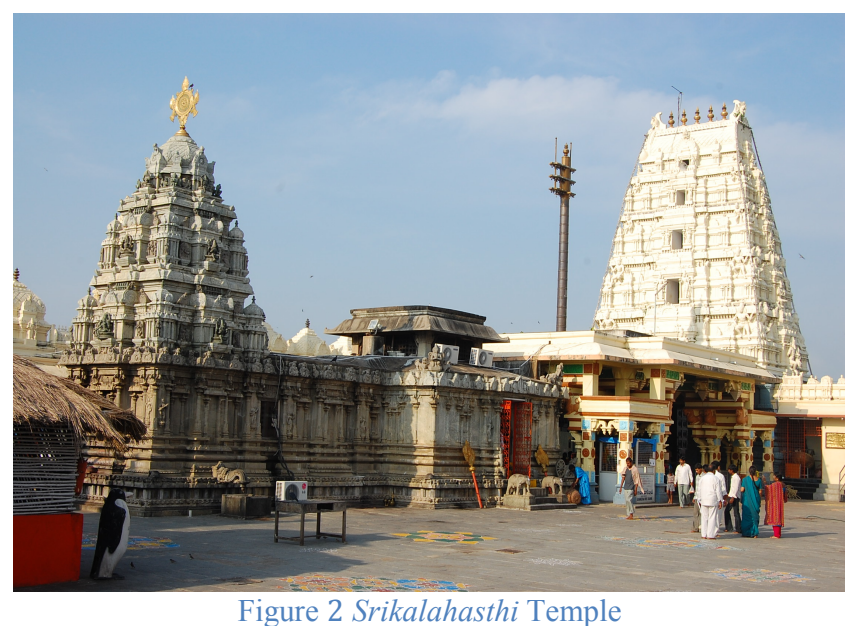

\subsubsection{Critical Issues}

The main Gopuram on the right side of the Temple was built in the $16^{\text {th }}$ century, as a symbol of victory is called the Rajagopuram and was 136 feet in height. It had been observed over the last decade that cracks had been appearing on the Gopuram and a critical crack developed 25 years ago had grown into a vertical fissure and ended at the base layer. This was specifically prominent few weeks before the collapse of the structure (see figure 3) and a commission was ordered to consider the issue. However, before any work of restoration could commence, the Gopuram collapsed at 8:30pm on May 26, 2010. (V.Sundaram, 2010)

The collapse had been attributed to the rampant bore well digging in the area as well as the occurrence of the 'Laila' cyclone in the state of Andhra Pradesh. An enquiry commission had been ordered to look into the issue and it was proposed that the Gopuram be rebuilt with support from the Archeological survey of India. On January 17, 2017, the new Gopuram was inaugurated. The new structure was supposed to be reminiscent of the past and was to include relics from the collapsed gopuram. However the new gopuram does not indicate in anyway which materials are new and which are old and is of different dimensions than the old gopuram (Indian Express news service, 2017).

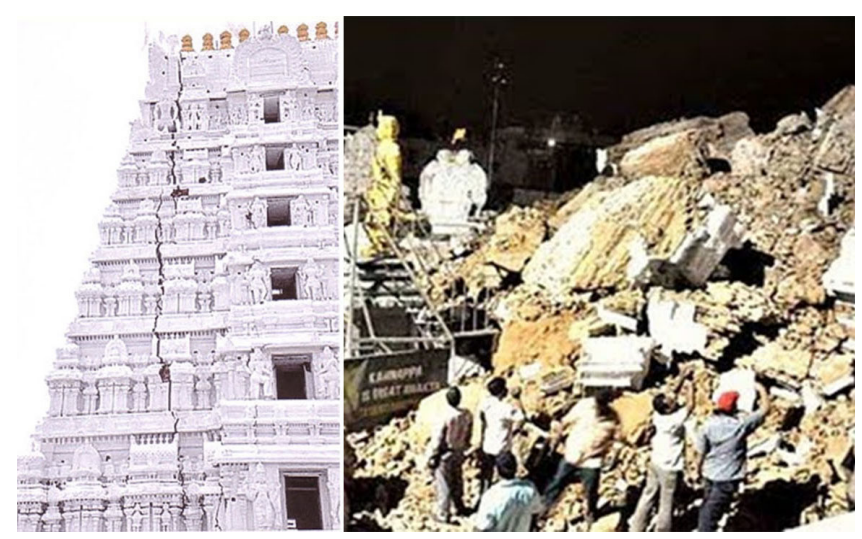

Figure 3 Gopuram before and after collapse (V.Sundaram, 2010) 


\subsection{CASE-STUDY 2 - SRISAILAM MALLIKARJUNA TEMPLE, Andhra Pradesh, India}

\subsubsection{General information - History}

The Mallikarjuna temple is located in the Srisailam village of Kurnool District in the South Indian state of Andhra Pradesh, with location co-ordinates $16.0740^{\circ} \mathrm{N}, 78.8686^{\circ} \mathrm{E}$. The Temple is situated on top of the picturesque Nallamala hills close to the River Krishna. This temple worships the lord Shiva, one of the principal deities of Hinduism.

Archeological studies suggest that inhabitation of Srisailam dates back to 30,000-40,000 years. Epigraphical evidences show relations to that the place was closely linked to the Satavahanas, the first rulers of the South Indian region. Inscriptional evidences suggest the Architectural features to belong to the Chalukya period (AD 624-848). The Kakatiyas (AD 953-1323) had contributed to the development of the temple. Later, renovations were introduced by the Vijayanagara rulers (AD 1336-1678). The construction of the Rajagopuram is accredited to Sri Krishnadevaraya of this dynasty. Since the construction of the temple occurred over a period of time, it can be observed that various elements of the temple are made of different materials. The main temple inner sanctum being made of stone, the surrounding gopurams are noted to be made of brick masonry (Srisailam Devasthanam, 2016).

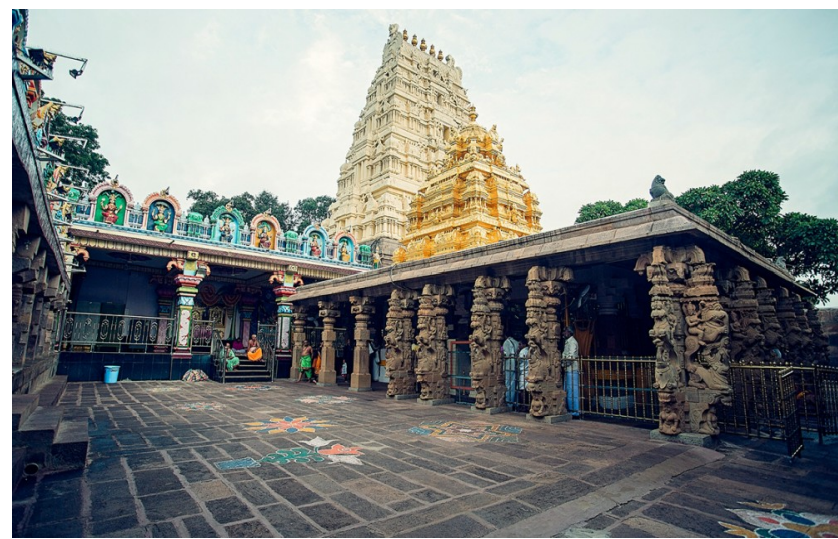

Figure 4 Srisailam Temple (Srisailam Devasthanam, 2016)

\subsubsection{Damage Assessment and Perspective of Rehabilitation Problems}

The Shivaji Gopuram as it is famously known can be dated to be about 500 years old. The $82 \mathrm{ft}$ high structure collapsed at $2.10 \mathrm{am}$ on October $3^{\text {rd }}, 2012$. Located on the northern side of the temple, the gopuram is believed to be constructed by the King Shivaji, hence the name. It had served as one of the main entrances to the Mallikarjuna temple of Srisailam. (The Hindu, 2012) Circa 196264 some cracks were noticed to develop on the gopuram due to stresses caused by the decaying of wooden beams inside the gopuram. The state government had then carried out the necessary repairs, which included cement plastering.

In 2010, an experts committee was established to examine the condition of the temple along with a few more monuments and it was noticed that the Shivaji gopuram was the weakest. A decision was then made to demolish it completely to rebuild a new one, but it did not happen due to concerns raised by the state archeological department. However, by 2012 , the situation had worsened and the internal cracks from before had worsened and penetrated to the exterior of the brick gopuram, while the wooden paneling on the interior was completely decayed, the internal plaster was deteriorated too and finally more than half of the structure collapsed. (YoungIntach,

2012)

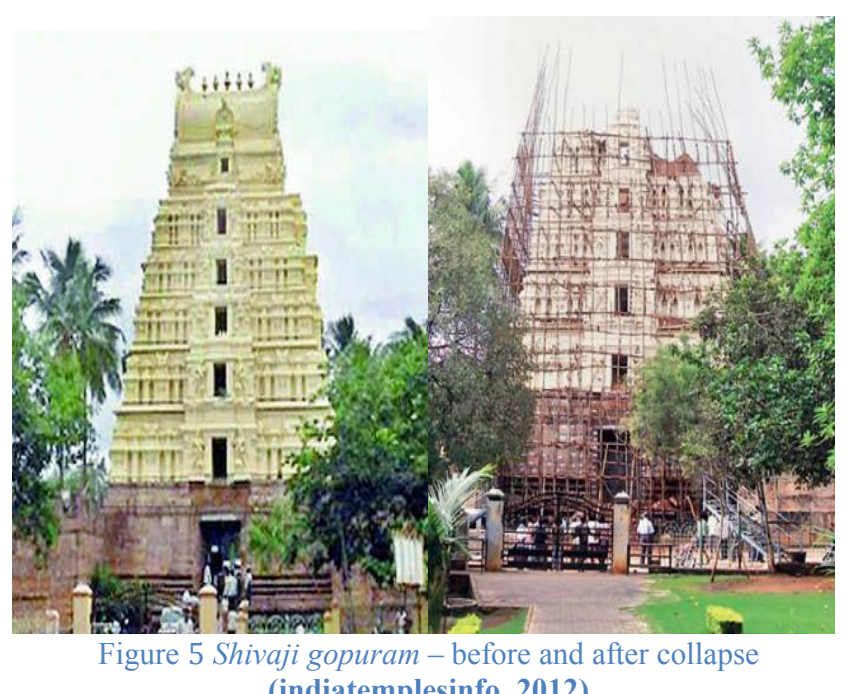

(indiatemplesinfo, 2012)

\subsection{CASE-STUDY - Synopsis}

The Srikalahasthi temple and the Mallikarjuna temple are two of the most famous temples in India for the devotees of the Lord Shiva. Everyday there are millions of devotees visiting these temples and many rituals are performed day and night in the premises of these temples. Maintenance in this context is always attributed to 'cleaning' of the temple and there is never mention of maintenance of the structure and monitoring is mostly absent. The lack of the above-mentioned aspects is the main reason for the critical scenarios in these temples. This also turns into a serious safety threat to the people visiting the temple. Hence it is important to raise awareness to the possibility of preventing such mishaps.

It can be observed in both the cases that maintenance or mainly the lack of it is the problem. Crack development was observed on both the structures; nevertheless, they were not monitored and the cracks increased exponentially in size leading to the collapse of the structure. The authorities that were instated to take care of the buildings were incapable of preventing the mishaps and furthermore the suggestions post these happenings were regarding the demolition of the existing structure and construction of a new structure very like the previous one. This approach constitutes the diminishing of the cultural value of the structure and the concept of preservation is lost. It is imperative that the Indian system incorporates some techniques adopted by other countries, such as preventive maintenance and planned conservation to safeguard its cultural built heritage. 


\section{MATERIALS \& METHODS FOR MONITORING}

\subsection{Italian Philosophy of conservation}

From 2004, a new legal framework has been introduced in Italy. The new Cultural Heritage Code (D. Lgs. 42/2004, art. 29) expresses Conservation as planned project that is a long-lasting process, surpassing the previous concept of "restoration". This long process is to be constituted of various other phases such as the study of the structure (assessment, documentation and analysis), prevention of mishaps, maintenance of the structure and restoration only if necessary. Furthermore, the law also states that maintenance included should be careful about the state of conservation and should monitor the changes occurring in the structure and adapt to it, instead of being just an automatic repetition of routines. The new code requires innovating the research of testing and analyzing. This requires the reorganization of the established testing techniques and innovative ones as well, according to effective and convenient procedures for monitoring. (Stefano Della Torre, 2005)

\subsection{Assessment}

Various Phases constitute the conservation process; assessment, documentation and analysis for the preliminary steps that guide towards further action of protection, maintenance and conservation.

Documenting heritage buildings means gathering and recording all pertinent data and information, both in written and visual forms. Documentation plays a pivotal role, as it is the first step when the mapping and identification of damages help the purpose of conservation. It helps plan the diagnosis and address the economic aspect for the next step of intervention for the project. Assessment of the building consists of visual analysis and preliminary tests to determine the immediate course of action. Generally, visual analysis such as the process of photogrammetry, rectification of images and laser scanning, infrared thermography and regular photographs taken for documenting the building, etc. are followed by tests to identify critical areas and then furthermore diagnostic tests are performed to comprehend the depth of the damage.

\subsection{Monitoring Through Diagnosis}

Over the past few decades, it can be observed that the restoration and rehabilitation of historic buildings happen only after a long period of misuse and low maintenance and sometimes due to lack of knowledge about the real state of damage, the restoration is not successful and the damages reoccur. Hence it is necessary to diagnose the state of the damage of the building accurately to avoid reoccurrences of damages or unsuitability of interventions. After preliminary tests and location of critical areas, more investigation needs to be done in the located damage areas to understand the intensity of the problem. Since properties of materials vary in historic buildings, it is imperative that each damage area is investigated separately.

These days research in the field of conservation of built heritage; have given path to different modes of testing to evaluate different parameters of historic buildings. Few requirements necessary for monitoring and testing techniques for planned conservation are mentioned below
- Rigorous but relatively simple

- Cheap but reliable

- Nondestructive or minimal destructive for repetition

- Monitoring instead of measurement taken once

- Controlling the risks that are present in the environment

- $\quad$ Procedures suitable of modification according the need in the site

- $\quad$ Based on remote control and imaging

- $\quad$ Short post processing phase

(Stefano Della Torre, 2005)

\subsection{Non-Destructive Testing}

Non Destructive Testing evaluates without causing any kind of observable damage and also do not provide direct details about the material properties of the materials. Thus, there is an unsubstantiated relationship between NDT results and the material properties of the masonry. However, they can provide a general understanding of the comparative characteristic of the materials being investigated. (A.Saisi, 2001) Some nondestructive tests include the use of dataloggers for information regarding the micro-climate in the building such as the temperature and relative humidity are also very helpful in monitoring the buildings. Others include thermal imaging through infrared thermography or by photos captured with ultra-violet radiation, photogrammetry and ultra-sound testing.

\subsubsection{Infrared Thermography}

Infrared thermography is an impressive non-destructive diagnostic method, as it is based on a characteristic of the materials i.e., the temperature and it doesn't involve any physical contact with the material involved.

The outcome of measurement is a thermal picture of the surface, in which the different colors correspond to various temperature levels of the surface target. The measurement accuracy depends on parameters like ambient temperature, wind speed, distance from the target, the weather. The use in the plan of conservation is often in the preliminary phase of the diagnostics, to map anomalies that have to be further investigated, and in monitoring the interaction between the environment and the surfaces of the buildings, inside and outside, with the aim to prevent damages due to humidity and temperature variations, rising damp, water and air leakages (Rosina, Diagnostics for the preservation plans of diffused historical heritage, 2010). The technique is particularly suitable for inspect large surface in a brief period (at optimal environment conditions, as often in South India are) and it could allow to early detect also the cracks patterns as soon as it appears if some periodical inspection is planned.

\subsubsection{Ultrasound Testing}

Ultrasonic velocity testing methods are commonly employed to determine various characteristics of unreinforced masonry and for purposes such as calculating the uniformity of the masonry; positions of voids, cracks, joints and estimation of the elastic properties of the masonry. These methods are especially useful in investigating historic structures where the masonry must be preserved and destructive tests cannot be used. The fundamental concept of this test is that a mechanical wave pulse is created in 
the masonry between two sensors, one where it is generated and the other on another part of the masonry surface to accept and record the wave. The properties and differences between the transmitted and received waves can provide information about the medium that the wave travelled through. (Manning, Ramos, \& Fernandes, 2014)

Application of this procedure in India seems like a feasible opportunity because of the use of stone as the ultrasound testing is particularly recommended for this kind of material because of the good and reliable results. The technique is appreciated because it is not destructive, but it is not very much recommendable forconservation plan, due to its "punctuality". It is related to points selected on a particular plane of the structure, nevertheless the results can be processed as images, by tomography, improving the communication of results and confront ability of them in time to discover any phenomenon that is increasing or evolving.

\subsubsection{Photogrammetry}

Photogrammetry has been used as a tool to aid the documentation of built heritage since ages past, earlier it was used to create scalable documents from two dimensional photographs. Augmentation of recent technologies along with the possibility of cloud-based processing has created new avenues to purse this procedure with better results in documenting historical buildings. This can be accomplished with a small amount of training, a photo Camera or a Smartphone, and an internet connection. Webservers that are based on applications manage the process; this includes image recognition, matching, stitching, threedimensional mesh creation and rendering. These cloud-based applications make three-dimensional photogrammetry more accessible and cost-effective. Progress in the fields of calculation software, model generation software, automation and sensor technologies have made possible the amplification in photogrammetric technology. Digital two-dimensional images when combined with the easily accessible photogrammetric software help in the process of documentation of historic sites effortlessly, and without the need for expensive and complicated equipment. (Church, 2016)

AS an example, this procedure was used in the documentation of the 16th century Pertev Paşa Mosque in Izmit, Turkey as a part of the IDEAS workshop in September 2015 hosted by the School of Architecture, University of Izmit. Close-range, cloud based threedimensional photogrammetry was used. The mosque is a single domed structure, built in the Ottoman reign, located at the eastern end of the Marmara region in the city of Izmit. The mosque sustained damage during an earthquake in 1999 and served as one of the study case of the international workshop.

The procedure of cloud based digital photogrammetry initiated with the collection of systematically taken digital images of the site. (Photograph quality dictates the accuracy and details of the final three-dimensional model). Prior planning is required to include a few control measurements before capturing photographs to provide a scale for the final finished model. Variables such as illumination, accessibility, obstructions, and sequence of the photograph are important considerations, especially with complex subjects or subjects with recurring features. Photographs are then uploaded to the cloud-based server for processing by automated modelling software (i.e. Autodesk ReMake). The software analyzes the two-dimensional images to create a threedimensional polygonal textured mesh model, which could be generated in several types of files that can be downloaded to a computer for post-processing. Sometimes multiples mesh models could be created separately and later joined together. A building's interior mesh model can be inserted into the building's exterior mesh model through various modelling software (such as Maya or Rhino).

Though there are limitations to this cloud based procedure such as the obstructions surrounding the building, the scale of the building and dimension accuracy. Features such as the low cost, accessibility, minimal field time, and simplicity of use make it viable option for documentation. This sequentially makes it a very lucrative procedure to be implemented for the Indian context.

\section{DISCUSSION AND CONCLUSION}

Preliminary assessment and diagnosis of the structure form the core of the Documentation of a historical building. Performing the above-mentioned tests provide a wealth of information that is essential for protecting the building. Anomalies can be detected and documented, which can be very helpful during repeated checks of monitoring of building. This keeps track of the critical areas and sometimes helps prioritize the damages that need to be considered in the order of criticality.

In the Indian context where 'cleaning' and 'repairing' form the main criteria of maintenance for a historic building. Introduction of monitoring as a part of maintenance could vastly improve the efforts of conservation. As Monitoring plays a fundamental role in the aim to save the building in the long-term, monitoring systems expend more knowledge of the most difficult properties to assess the long-term behavior of historical structures. These monitoring techniques are less expensive when compared to the massive undertaking of the construction of a new building that essentially is a copy of the previously existing building. These technologies should be made more accessible and understandable for the members of the various departments that are presently undertaking the responsibility of maintenance of historical structures in India.

An additional step in this course can be introduced in the form of structural monitoring. Looking at more innovative technologies in this context, Architects and civil engineers working in the field mostly use most of these systems. Unfortunately, such options are steeply priced in the emergent countries and are usually reserved for buildings in critically endangered conditions. However, it is also vital that with the advancement of science, these technologies be made easier for other countries where less technical knowledge is shared, for those who work to maintain the historical structure, to appropriately evaluate the structural interventions on periodic checks rather than waiting for something drastic to happen. Recent studies propose innovative ideas with the purpose of bringing structural monitoring techniques to sites that cannot afford a high budget to prevent the endangered situations for historic buildings. 
This knowledge should be made more accessible and should be more simplified to make it reach the most remote corners of the country to ensure proper maintenance and monitoring of the historic buildings. Workshops and courses could be introduced to help the employees of the endowment departments of the various states in India as well as other organizations that are involved in Heritage protection. Conflicting ideologies of the life cycle process followed in historic times and the new interest generated in the population to protect the built heritage could be accounted to the present scenario of conservation of built heritage in India

Multi-disciplinary approaches between Civil and Electronic engineering have made this possible. One such example was developed as a part of the Masters' thesis Project of the Structural analysis of monuments and historical constructions master's program at the University de Minho in Portugal. An on-site easily constructible monitoring system was devised. Dividing it into smaller components, choosing different technologies and possibilities that could lead to a low-cost solution was the approach applied. This was then tested on a real case study and the performance, costs and time consumptions were analyzed.

This system included static and dynamic monitoring with the help of automated algorithms. It was built by assembling solar powered battery system (Energy source) connected to an Arduino digital micro controller along with an analog temperature and humidity sensor fitted to an LVDT solatron (linear variable differential transformer - to measure linear displacement) with a Bluetooth module, XBee module (for network forming) and a micro SD card (for data transfer). (Basto, 2015)

The Prototype was then tested for monitoring the displacement of a crack in a particular wall of a building. The results displayed were a compilation of the values of Temperatures and humidity over a period of time and the crack width changes in this period. Parallelism was observed between the crack width and the temperature. (Basto, 2015)

The development of such systems combined with increased awareness of their advantages by the maintenance systems of historical constructions could lead to the beginning of a new era of digital documentation of Built heritage. Well-monitored structures have well timed interventions, which lead to lower maintenance costs making the process more commonplace. This awareness could make our heritage Flourish and survive for our future generations.

\section{REFERENCES}

A.Saisi, L. B. (2001). State of the Art of Research on Historic Structures in Italy. ADVANCED RESEARCH CENTRE FOR CULTURAL HERITAGE INTERDISCIPLINARY PROJECTS.

Architecture Imprints. (2004, october 15). Comments on the Charter, In Charter for the Conservation of Unprotected Architectural Heritage and Sites in India (Working Papers).. (A. G. Piplani, Ed.) Retrieved from Architexturez South Asia: https://architexturez.net/doc/az-cf-21206

Basto, C. A. (2015). Study on possibilities for low-cost monitoring of historical structures. Thesis, Erasmus
Mundus, ADVANCED MASTERS IN STRUCTURAL ANALYSIS OF MONUMENTS AND HISTORICAL CONSTRUCTIONS, spain.

Chandra, S. G. (2000). Srikalahasthi. Retrieved from srikalahasthi temple website: http://www.srikalahasthitemple.com

Domenica Paolettia, D. A. (2013, April). Preventive thermographic diagnosis of historical buildings for consolidation. Journal of cultural heritage, 14(2), 116121.

Fergusson, J. (1910). History of Indian and Easter Architecture (3rd edition 1997 ed.). mumbai, maharashtra, india: Low price publications.

Government of India. (2013, july). Central Public Works of India. Retrieved from National portal of India: http://cpwd.gov.in/Publication/ConservationHertBuildin gs.pdf

Government of India. (2014, october 2). sawchh bharat. Retrieved from national portal of india: https://swachhbharat.mygov.in/sb-activities

Government of India. (2015, january 21). hridayindia. Retrieved from indian government portal: http://hridayindia.in

Indian Express news service. (2017, january). Indian express news - states. Retrieved from new indian express: http://www.newindianexpress.com/states/andhrapradesh/2017/jan/13/rajagopuram-at-srikalahastitemple-to-be-opened-on-january-18-1559179.html

indiatemplesinfo. (2012, october). Retrieved from indiatemplesinfo:

http://www.indiatemplesinfo.com/india/srisailamshivaji-temple-gopuram-collapses/

Koduveliparambil, J. J. (1997). Construction Practices in Traditional Dwellings of Kerala, India. thesis disertation, McGill uniersity, department of architecture.

Manning, E., Ramos, L. F., \& Fernandes, F. M. (2014). Direct Sonic and Ultrasonic Wave Velocity in Masonry under Compressive Stress. Internaational masonry society. Guimarães .

Rosina, E. (2010). Diagnostics for the preservation plans of diffused historical heritage. KARSILASMALAR: TURKIYE VE ITALYA'DAN ORNEKLERLE MIMARI YAKLASIMLAR. Kocaeli.

Rosina, E. (2010, April 26). Diagnostics for the preservation plans of diffused historical heritage. KARSILASMALAR: TURKIYE VE ITALYA'DAN ORNEKLERLE MIMARI YAKLASIMLAR.

Srisailam Devasthanam. (2016). Srisailam mallikarjuna temple. Retrieved from Srisailam online: http://www.srisailamonline.com/history.html

Srivathsan, A. (2011, february 22). Unearthing the past. The Hindu.

Della Torre, S., E. Rosina. (2005). EARLY DETECTION AND MONITORING PROCEDURES BY MEANS OF MULTISPECTRAL IMAGE ANALYSIS. 8th International Conference on "Non Destructive Investigations and Micronalysis for the Diagnostics and Conservation of the Cultural and Environmental Heritage.". Lecce.

The Hindu. (2012, october 4). Gopuram Collapses in Srisailam. The Hindu.

Della Torre, S. (2010). Conservation of built cultural heritage, laws enabling preventive approach, the case of italy. 
Retrieved from https://www.researchgate.net/publication/281103761_C onservation_of_built_cultural_heritage_laws_enabling preventive_approach_the_case_of_Italy_in_M_Gustin T_Nypan_eds_Cultural_Heritage_and_legal_Aspects_i n_Europe_Koper_2010_pp_168-178

TTD. (2015). Tirupati Tirumala Devasthanam. Retrieved from Tirumala.org: http://tirumala.org/ArjithaSevas/Abhishekham.aspx

V.Sundaram. (2010, june). ennapadampanchajanya. Retrieved from

http://ennapadampanchajanya.blogspot.it/2010 $06 \quad 01$ archive.html

Ministero per i Beni Culturali e Ambientali ISTITUTO CENTRALE DEL RESTAURO PIANO PILOTA PER LA CONSERVAZIONE PROGRAMMATA DEI BENI CULTURALI IN UMBhttp://www.istitutomnemosyne.it/dmdocuments/1_PROGETTO_ESECUTIVO.pdfR IA PROGETTO ESECUTIVO Roma, TECNECO 1976

Website accessed on April 17, 2017

\section{ACKNOWLEDGEMENT}

I would like to express my sincere and heartfelt gratitude to Professor. Elisabetta Rosina without whose support, encouragement and valuable contributions this research paper would not have been possible.
Vardia, S. (2008). Building Science of Indian Temple architecture. thesis dissertation, Universidade do Minho, braga.

YoungIntach. (2012, october). heritage alerts. Retrieved from YoungIntachexplorer: http://youngintach.org/heritagealerts-oct2012.asp

YOUNGINTACH. (2016, May). Conservation Activities education. Retrieved from youngintachexplorer: http://youngintach.org/heritage-alerts-may16.asp 